\title{
Application of Portable Gasification Stove in Supporting Disaster Response
}

\author{
Habib A. Nurusman ${ }^{1,2}$, Wira Widyawidura ${ }^{1,2}$, M. Noviansyah Aridito1, \\ Amin Nurohmah ${ }^{2}$, Agus Priyono ${ }^{2}$ \\ Environmental Engineering Department, Universitas Proklamasi 45 \\ Yogyakarta \\ Center for Energy and Environmental Studies, Universitas Proklamasi 45 \\ Yogyakarta \\ Email: habibnurusman@gmail.com
}

\begin{abstract}
The application of micro-gasification stove technology for outdoor and disaster response activities is one of the renewal efforts in the utilization of biomass waste to energy. This study uses a portable micro-gasification stove type of natural draft which consists of three important compartments, namely the equalizer chamber, reactor chamber, and chimney. The unique ventilation of the reactor and chimney in this furnace will form a vertically spiraled air flow. This air flow will help complete combustion throughout the reactor chamber and accelerate the process of heating and gasification. Empirical test on this stove has been done by using a naturally dried twig and some kind of processed biomass (briquette/pellets). The peak temperature of the fire was not much different, ranging from $700{ }^{\circ} \mathrm{C}$ to $900{ }^{\circ} \mathrm{C}$. With a total mass about 250 grams for each fuel (dry twigs, wood powder briquettes, and paper waste pellets), the duration of the flame occurs between 15 to 30 minutes depending on the fuel variant. In this experiment, the resulting fire was able to boil water with a volume of $500 \mathrm{ml}$ in less than 7 minutes. While the remaining combustion, the live coals in the reactor is still able to warm water with the same volume from room temperature, about 28 ${ }^{\circ} \mathrm{C}$ to $80^{\circ} \mathrm{C}$ without any addition of fuel. Considering the performance and ease of procurement, storage, and distribution of fuel, the portable micro gasification stove is feasible to serve as a tool for disaster response support.
\end{abstract}

Keywords : Portable gasification stoves, biomass waste, outdoor activities, disaster response. 


\section{Introduction}

Physical factors such as geology and geomorphology of Indonesia illustrate that Indonesia is a prone risk area, where one of the biggest disaster risks is in the ring of fire with more than 90 volcanoes [1]. Based on Indonesia's disaster statistics data from 2006 to 2015 it was noted that 9 types of disasters in Indonesia have resulted in deaths of 11,476 people, with the total affected reaching of $10,054,332$ and total losses has reached $\$$ $11,167,826[2]$.

These disaster cases resulted in the victims fleeing to refugee shelters set by the government. As usual, the energy support equipment in the shelter, especially for cooking still relies on relatively vulnerable fuel oil in procurement, storage, and distribution. Whereas the supply of oil and gas in emergency disasters will tend to be more difficult to meet, when, the amount of biomass fuel is actually quite abundant. Therefore, cooking stove technology is required to apply in the disaster response condition in order to convert biomass (non-fossil) fuel into heat energy by considering the emission factor. One of the energy conversion technologies that are considered relevant for this condition is a gasification micro stove.

According to Red Cross and Red Crescent movement, who framed a Humanitarian Charter and identified Minimum Standards to attain in disaster assistance, there are requirements for the stove on disaster response including [3]:

- existing local practices should be taken into account in the specification of stove and fuel solutions

- This could include possible changes to the type of food to be prepared such as any rations provided by food assistance programmes e. $\mathrm{g}$. pulses in require the considerable cooking and the hence fuel,

- Where displaced populations are accommodated in mass shelters, communal or centralized cooking and heating facilities are preferable to the provision of individual household stoves, to minimise fire risks and indoor smoke pollution,

- Concluding from energy conservation, United Nation High Commisioner for Refugees (UNHCR) proposed the types of stove that have been proved for energy saving and more environment-friendly particularly for developing countries. These types including (a) improved stove; (b) mud stove; (c) kerosene stove; and (d) solar cooker (figure 1) 

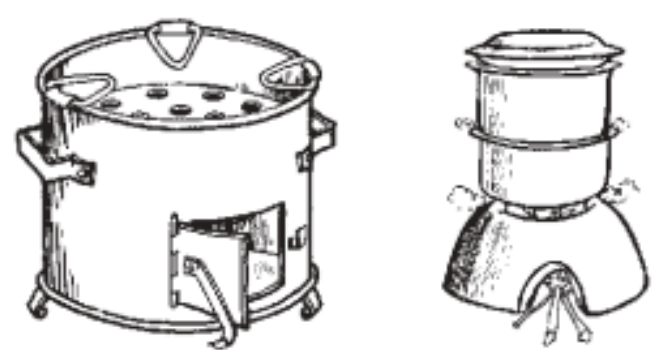

(a)



(c)

(d)

Figure 1. Alternatives stove types that appropriate for refugees in developing countries: (a) improved stove; (b) mud stove; (c) kerosene stove; and (d) solar cooker [4].

The focus of this research is on the use of the improved stove or better known as micro gasification stove. Gasification is the proved technology in order to convert carbonaceous feed, such as coal, petroleum coke (petcoke), heavy residual oil, wastes, and biomass into valuable products mainly via syngas (synthesis gas) route [5]. Gasification is the partial combustion of solid biomass in presence of controlled air by a thermochemical process, which leads to the generation of a mixture of combustible gases Hydrogen $\left(\mathrm{H}_{2}\right)$, carbon monoxide (CO), Methane $\left(\mathrm{CH}_{4}\right)$, nitrogen (N2) and other gases. The heating value of this gas is in the range of 4-6 $\mathrm{MJ} / \mathrm{Nm}^{3}$, or about $10-15 \%$ of the heating value of natural gas [6].

Gasification is the proved technology in order to convert solid biomass into syngas (carbon monoxide, hydrogen, and carbon dioxide), which is achieved by igniting these materials in the presence of controlled air by thermo-chemical process [5] [6] [7]. There are four stages in the microgasification stove: 1) biomass drying, in which water vapour is given off; 2) pyrolysis, in which temperatures over $300{ }^{\circ} \mathrm{C}$ and limited oxygen from the primary air flow generate energy-rich gases, leaving the solid black carbon (char, also known as biochar); 3) Migration of the gases (also known as wood gases) upward to the second combustion zone which when mixed with oxygen (secondary air flow), combusts; and 4) char combustion and conversion to ash. This last stage can be interrupted and the char conserved as biochar for its soil amendment value [8]. 
This study will examine the performance of a portable microgasification stove, a natural draft type developed by Centre for Energy and Environmental Studies (PSEL) of UP45 using variations of biomass fuel. It is expected that this research will become the first reference in the improvement of PSEL of UP45 gasification micro furnace with the aim of supporting survival activities and disaster emergency situations.

\section{Research methodology}

In this research, a natural portable gasification or natural draft has been designed as a development product by PSEL UP45 named TAGS-1. The furnace consists of three important compartments, namely the equalizer chamber, reactor chamber and chimney (figure 2). Some types of biomass fuel; natural dry twig waste, briquettes from waste wood powder and pellets from paper waste, will be tested on the stove. All experiments will be conducted in open space as a form of the field test. During the experiment will be observed several things: 1) the ease of ignition of biomass fuel, 2) the rate of furnace heating, 3) the duration of flame and coals, 4) the effectiveness of stove for cooking water.

Levels of ease of fuel ignition based on selected preparation actions. Starting from the preparation of the particle size, the fuel supply in the reactor and the type/amount of fuel in the trigger used.

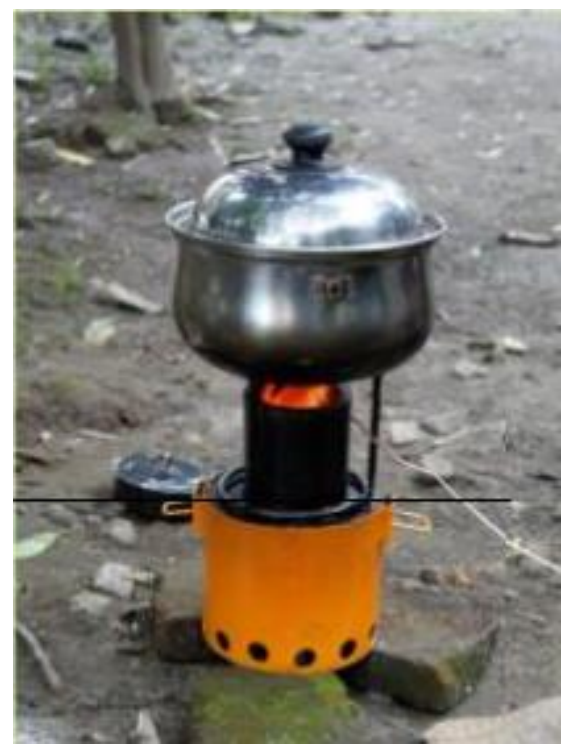

Figure 2. TAGS-1 micro-gasification stove with natural draft type used in the study 
Furthermore, the heating rate of the stove is observed by measuring the temperature rise every 2 minutes at the stove output by continuously using the thermocouple. This temperature measurement is carried out under two conditions; the first condition is carried out as long as there is still a flame, while the second condition is the condition after the fire went out and leaves only the embers.



a) Measurements of stove and water temperature at the time of a flame

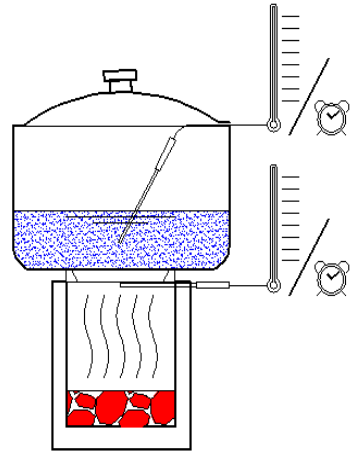

b) Measurement of stove and water temperature at the time of embers.

Figure 3: Concepts of Stove Preparation, Vessel and Thermocouple

At the same time, measurements have been made on each of these conditions for changes in the temperature of the boiling water. Two stainless sealed vessels containing $500 \mathrm{ml}$ water are cooked over the furnace alternately according to the conditions of the furnace flame. From these measurements, we will know the effectiveness of boiling water in each condition. With this objective, a schematic of the temperature measuring device as shown in Figure. 3 is developed.

\section{RESULT AND DISCUSSION}

\subsection{Ignition of Stove}

The method and preparation step of fuel ignition in the stove is strongly related to the type of fuel. The dry twig particles were formed with an average length of $2-3 \mathrm{~cm}$ and the wood briquette particles were formed 
with $\varnothing 6 \times 1.5 \mathrm{~cm}$ size, while the paper waste pellets did not require any special treatment, with an average size of $\varnothing 1.5 \times 4 \mathrm{~cm}$.

The starter used is the waste from the wood shrinking machine for fuel dry twigs and briquettes from the waste of wood powder. As for paper waste pellets, the gasoline will be used as a fuel trigger.

On dry twigs, 25 grams of wood shavings as triggers are arranged normally without compacting on the reactor side with a $2 \mathrm{~cm}$ diameter center-sized cavity. Then dry twigs are arranged upright enough solid, above the wood shavings waste around the side of the reactor and still leaves the center of the cavity. The ignition is done by lighting the fire on the wooden sack at the bottom center. After ignition, the wooden branches are added continuously to keep the flame. This is because, the volume of twigs varies greatly, depending on the mass of the branch type, so not all fuel can be put in one time. The fuel loading rate in this study was $10 \mathrm{gr}$ per minute.

In line with the ignition of stoves with dry twig fuel, triggers from shaved wood waste are used to ignite the wood fuel briquettes with the same mass. The difference lies in the fuel inflowing process, with much better density, 250 gr briquettes of wood powder waste can be used in a single process. For the use of pellets from waste banknotes, the starter used is gasoline, because this type of pellet is not flammable if it is only triggered by shaved wood. Fifteen $\mathrm{ml}$ of gasoline used to soak about 75 grams of pellets, then subsequently all the pellets (250gr) are arranged in the reactor with a gasoline-soaked pellet position, at the top.

Table 1: Assessment of Level of Ease of Ignition using Biomass Fuel

\begin{tabular}{|c|c|c|c|}
\hline \multirow[b]{2}{*}{ Score point } & \multicolumn{3}{|c|}{ Type of Fuel } \\
\hline & $\begin{array}{l}\text { Twigs } \\
\text { dry }\end{array}$ & $\begin{array}{c}\text { Wood } \\
\text { powder } \\
\text { briquettes }\end{array}$ & $\begin{array}{c}\text { Paper } \\
\text { waste } \\
\text { pellets }\end{array}$ \\
\hline $\begin{array}{l}\text { Formation of } \\
\text { particles }\end{array}$ & 3 & 2 & 1 \\
\hline Arrangement & 3 & 2 & 1 \\
\hline $\begin{array}{l}\text { Number } \\
\text { starters }\end{array}$ & 2 & 2 & $3^{*}$ \\
\hline $\begin{array}{l}\text { Length } \\
\text { ignition }\end{array}$ & 1 & 2 & 2 \\
\hline & 9 & 8 & 7 \\
\hline
\end{tabular}

*) For starter use Gasoline 
A scoring step should be taken to determine the most appropriate fuel to use with a scale of numbers between 1-3. The highest or the longest treatment amount would earn the highest value based on the intensity of the treatment. The fuel which has the lowest value indicating that the fuel is easiest to be turned on. The overall result of the assessment of the ease of ignition of biomass fuel in the gasification stove can be seen in Table 1.

\subsection{Stove Performance}

Measurements for stove work are carried out under two conditions. The first condition is when the flame is still present with three stages to go; a) preparation stage, b) growth stage, and c) Holding stage. The preparation stage is the time range that starts from the ignition process of the fuel trigger until some of the fuel has been burned. While the growth stage (growth period) is the time range from when the fuel has been burned followed by the development of flame and the stove output temperature reached $500{ }^{\circ} \mathrm{C}$. The Holding stage is the time range from the time the output temperature of the stove $500{ }^{\circ} \mathrm{C}$ to the fire goes out. The second condition is the time shortly after the fire goes out and leaves a coal flame that still has the potential to provide the calorific value. Measurements are limited only until the temperature has dropped to $150{ }^{\circ} \mathrm{C}$. This condition is also known as Temperature Down Period (TDP).

In general, dry twig ignition is faster than other fuel ignition, because it only takes 2-4 minutes, while briquettes and pellets take 6 minutes to burn. This period is shown in Graph 1 with a time value marked as negative. The growth stage is characterized by the development of fire and temperature. At zero minute or the beginning of the growing stage, the temperature has reached above $300^{\circ} \mathrm{C}$. Three types of fuel reached temperatures above 500 ${ }^{\circ} \mathrm{C}$ for less than two minutes, except for Fuel A which takes almost 4 minutes.

Although the accomplishment of fuel temperature (twigs) A is not too high, which is $623{ }^{\circ} \mathrm{C}$, the longest duration of this fuel is reaching the $32^{\text {nd }}$ minute or about 28 minutes. The cause factor is caused by the more volume or content, so the availability of supply becomes longer. Similarly, it also occurs in the twig fuel $\mathrm{B}$, which has a lifetime of up to 22 minutes, with the highest temperature of $716^{\circ} \mathrm{C}$. The pellet fuel from waste paper can last up to 26 minutes with the high temperature of $710{ }^{\circ} \mathrm{C}$. While wood powder briquettes only lasted 16 minutes with the maximum temperature of $867^{\circ} \mathrm{C}$.

The gusts of the wind are quite annoying, thus affecting the stability of temperature attainment in the holding stage range causing the 
temperature chart record to fluctuate. In the use of dry twig fuel, the fluctuation value is also influenced by frequency and volume of fuel addition. The longer the lag time of fuel increasing, the higher the fluctuation will occur and the recovery time will be longer than usual. Even the delay of inserting the supply could be the cause of the extinction of fire. Likewise, if the volume is excessively added, this will have an impact on the decrease in temperature and furnace burning capability to the extinction of fire.

While there are different treatments on briquette and pellet fuel, with better density, the volume becomes more compact. So that the mass amount that can be put into the reactor becomes more than usual. In this research, the loading of $250 \mathrm{gr}$ briquettes and pellets can only be done in one process, so the holding stage is not interrupted by the addition of fuel.

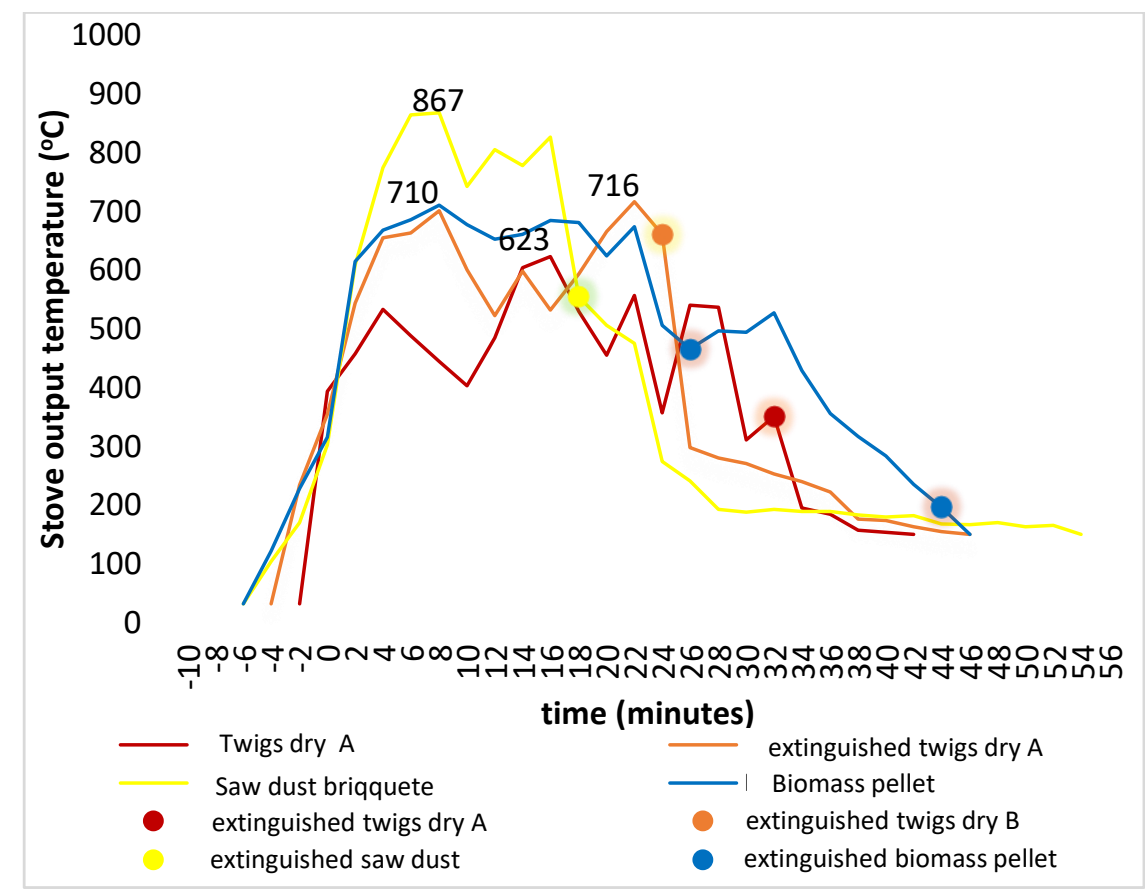

Graph 1. Heating rate at the stove output based on the type of fuel used

From the beginning of the growing period to the end of the holding period, $500 \mathrm{ml}$ of water is cooked in a closed stainless vessel and recorded at each change in temperature. The development of the output temperature is proportionate to the temperature of the water. At minute zero, the twin fuel heating rate reaches higher temperatures, so the temperature of the water cooked with wood becomes faster. However, as the temperature reaches the holding period, the temperature of the water with briquette and pellet fuel is relatively faster up to the boiling point $\left(98^{\circ} \mathrm{C}\right)$. 
In the test of cooking power, a twig fuel capable of cooking water to boil with less than 12 minutes. The better results will be shown on the use of pellet fuel, ie less than 10 minutes. While the best result is on the use of twig fuel B and wood powder briquettes able to cook until boiling point for less than 8 minutes. The rate of heating during the cooking process of water with some of these fuels will be shown in Graph 2.

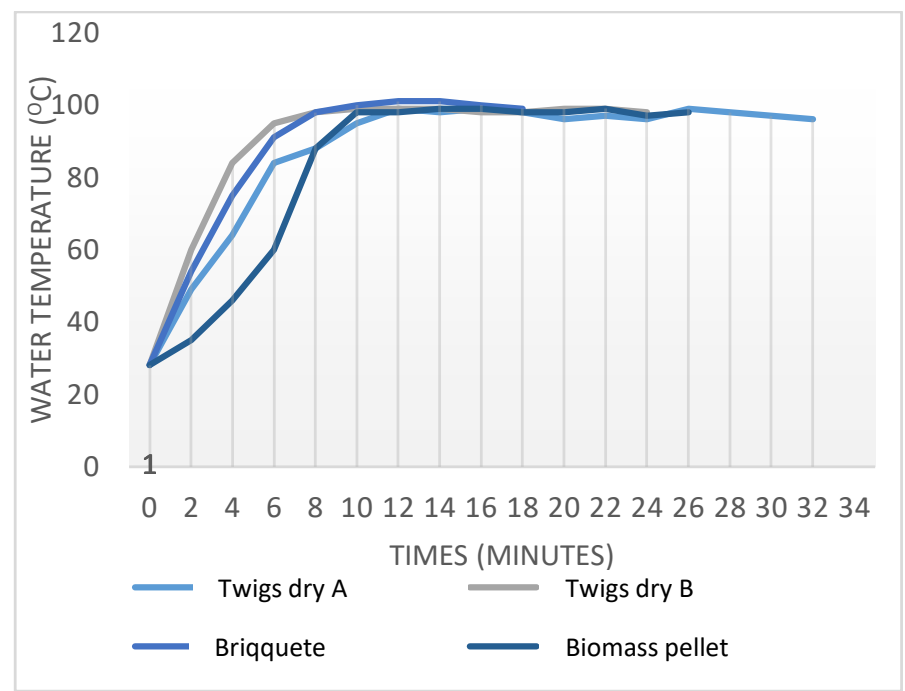

Graph 2. Heating rate of water is cooked by fire from several types of fuel.

The temperature of the burning coal combusted is still high enough, this condition can be utilized to heat water or other cooking needs until the coals run out. The rate of temperature drop will be related to the previous temperature ie the density of the fuel material. The higher the temperature at the time the fire goes out and the more solid the fuel, causing the coals to tend to have longer TDP time. 
The highest water temperature performance in this period was $78^{\circ} \mathrm{C}$ obtained from briquette fuel with a TDP 150 over 36 minutes. In second place is pellet; with the achievement of water temperature of $72^{\circ} \mathrm{C}$ with the value of TDP 150 reaching 20 minutes. For dry twigs, the water temperature reached is $60{ }^{\circ} \mathrm{C}$ with a TDP 150 reaching 26 minutes. The rate of water heating with burning live coal showed on graph 3

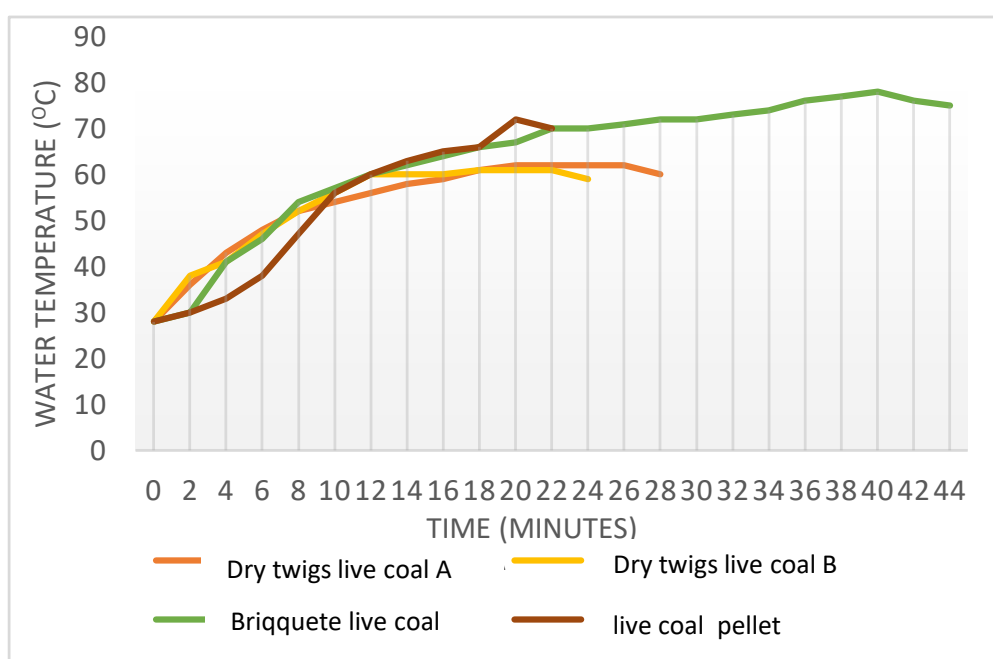

Graph 3: the Heating rate of water with burning live coal combusted from several types of fuel.

\section{CONCLUSION}

Based on the test results, the TAGS-1 micro-gasification stove can be used with a variety of biomass. Starting from natural waste biomass waste (twigs/wood) to fuel processed waste biomass (briquettes and pellets). In determining the best combination in supporting the performance of the gasification stove, it is necessary to assess the value of the ignition speed, the growing period, the holding period, the TDP value and the ease of storing the fuel stock.

Table 2. Stove Performance Evaluation by Type of Fuel

\begin{tabular}{|l|c|c|c|}
\hline \multirow{2}{*}{ Score point } & \multicolumn{3}{|c|}{ Type of Fuel } \\
\cline { 2 - 4 } & $\begin{array}{c}\text { Twigs } \\
\text { dry }\end{array}$ & $\begin{array}{c}\text { Wood } \\
\text { powder } \\
\text { briquettes }\end{array}$ & $\begin{array}{c}\text { Paper } \\
\text { waste } \\
\text { pellets }\end{array}$ \\
\hline Ease of ignition & 3 & 2 & 1 \\
\hline $\begin{array}{l}\text { Initial } \\
\text { temperature } \\
\text { rate (growing) }\end{array}$ & 1 & 2 & 3 \\
\hline
\end{tabular}




\begin{tabular}{|l|c|c|c|}
\hline $\begin{array}{l}\text { Highest } \\
\text { temperature } \\
\text { accomplishment }\end{array}$ & 3 & 1 & 2 \\
\hline Holding time & 2 & 3 & 1 \\
\hline TDP & 3 & 1 & 2 \\
\hline Storage & 1 & 3 & 2 \\
\hline & 13 & 12 & 11 \\
\hline
\end{tabular}

From Table 2., it can be concluded that pellets are the most appropriate fuel for TAGS-1 stoves in an emergency situation. Although the fossil fuel is still needed in ignition process, pellets have a good level of practicality and combustion performance. In terms of the storage and the price, pellets are easier and cheaper than fossil fuels such as kerosene or gas.

The selection of pellets as the best combination for the TAGS-1 stove does not rule out the use of other fuels, especially natural fuels such as twigs and wood. Considering there is no guarantee of supply stability and the stock of processed biomass and other fuels including oil and gas in emergency situations, while natural biomass waste is still easy to find.

\section{References}

[1] R. Y. Intarti, I. S. Fitrinitia, M. R. Widyanto and H. A. Simarmata, "Towards Disaster Management in Indonesia Case Studies: Jakarta and Yogyakarta Provinces," International Journal of Disaster Recovery and Business Continuity, vol. 4, pp. 11-22, 2013.

[2] CFE-DMHA, Indonesia Disaster Management Reference Handbook, The Center for Excellence in Disaster Management and Humanitarian Assistance, 2015.

[3] The Sphere Project, "The Sphere Project: Humanitarian Charter and Minimum Standards in.," The Sphere Project, Geneva, 2004.

[4] UNHCR, Cooking Options in Refugee Situation: A Handbook of Experiences in Energy Conservation and Alternative Fuel, Geneva: UNHCR, 2002.

[5] M. Khosravi and A. Khadse, "Gasification of Petcoke and Coal/ Biomass Blend," International Journal of Emerging Technology and Advanced Engineering, vol. 3, no. 12, pp. 167-173, 2013.

[6] K. A. Motghare, A. P. Rathod, S. S. Waghmare, K. L. Wasewar, N. K. Labhsetwar, "Performance Evaluation and Heat Transfer Studies on Biomass Gasifier Cook-Stove," International Journal of Application or Innovation in Engineering \& Management, vol. 4, no. 5, pp. 352-361, 2015.

[7] P. R. Sonarkar, E. A. Mardikar, S. Gupta, S. S. Dhabu and A. S. Chaurasia, "Performance Evaluation , Economic Analysis and Design of Biomass - Based Modified Purti Gasifier Stove," Journal of Scientific \& Industrial Research, vol. 76, no. 2, pp. 110-114, 2017. 
[8] D. Lotter, N. Hunter, M. Straub and D. Msola, "Microgasification Cookstoves and Pellet Fuels from Waste Biomass : A Cost and Performance Comparison with Charcoal and Natural Gas in Tanzania," African Journal of Environmental Science and Technology, vol. 9, no. 6, p. 573-583, 2015. 